\title{
Implementation of a Standardized Admission Hyperglycemia Insulin Order Set in a Veterans Hospital
}

\author{
Erin K. Yeung*, Mark Wong and Dana Wong \\ Department of Pharmacy Services, South Texas Veterans Health Care System \& The University of Texas Health Science Center San Antonio, USA
}

Submission: May 04, 2018; Published: May 16, 2018

*Corresponding author: Erin K. Yeung, Department of Pharmacy Services, South Texas Veterans Health Care System, San Antonio, TX, Pharmacotherapy Education \& Research Center, The University of Texas Health Science Center San Antonio, San Antonio, TX, USA, Email: erinkyeung@gmail.com

\author{
Abstract \\ Purpose: The efficacy of an implemented hyperglycemia admission insulin order set containing basal-bolus-correction regimens to facilitate \\ protocol-adherent prescribing in non-critically ill patients was evaluated.
}

Method: In this retrospective, single-center, observational study, patients age 18 years or older with a history of type 2 diabetes or admission blood glucose $>180 \mathrm{mg} / \mathrm{dL}$ were identified through electronic medical record review of patients admitted to medicine wards. Patients were excluded if admitted to intensive care or surgical units during hospitalization, identified to have a history of type I diabetes, treated for diabetic ketoacidosis, pregnant, or allergic to insulin. Patients were evaluated pre- and post-protocol implementation. The primary endpoint was mean hospitalization glucose levels. Secondary endpoints included: percentage of patients with average hospitalization glucose $<180 \mathrm{mg} / \mathrm{dL}$, percentage of basal insulin utilization, and hypoglycemia incidence.

Results: A total of 200 patients were included in this study, with 100 patients in each group. Average hospitalization glucose was not significantly lower in the post-implementation group compared to the pre-implementation group ( $169 \mathrm{vs} .177 \mathrm{mg} / \mathrm{dL}$, $\mathrm{p}=0.33)$. More patients in the post-implementation group had mean hospitalization glucose $<180 \mathrm{mg} / \mathrm{dL}$, though this was not significant ( 66 vs. $55 \%$, p=0.15). However, percentage of patients with basal insulin use did not change ( $43 \%$ vs $44 \%, p=1.00)$. There was no difference in hypoglycemic episodes ( 27 vs 24 events, $\mathrm{p}=0.75$ ).

Conclusion: The new basal-bolus-correction insulin order set at STVHCS is not associated with any difference in inpatient hyperglycemia control. Education at multiple interdisciplinary levels is required for effective hyperglycemia protocol implementation.

Keywords: Hyperglycemia; Long-acting; Insulin; Rapid acting; Blood glucose; Clinical protocols; Diabetes mellitus.

\section{Introduction}

Inpatient hyperglycemia is a common problem during hospitalization affecting numerous patients across institutions worldwide. Diabetes mellitus was associated with over 7.7 million hospitalizations in the United States in 2008, contributing to the incidence of inpatient hyperglycemia and increased hospital costs [1,2]. The management of inpatient hyperglycemia is affected by a multitude of factors, including acute illness, concurrent medications, inconsistent caloric intake, and insulin administration [3]. Stress hyperglycemia and various medications such as corticosteroids, calcineurin inhibitors, and atypical antipsychotics can increase glucose levels in patients, with or without diabetes mellitus [4]. Additionally, outpatient oral antihyperglycemic agents are typically discontinued during hospitalization to prevent complications with inpatient management, furthering the risk of hyperglycemia. Conversely, inconsistent dietary intake due to illness-associated loss of appetite, "nothing by mouth" (NPO) dietary precautions, and improper insulin use may increase the risk of hypoglycemia [4]. Hyperglycemia in hospitalized patients with or without diabetes mellitus has significant impact on patient care as it has been associated with worsened outcomes, including increased rates of infection, longer lengths of stay, and increased mortality [57]. Therefore, effective inpatient hyperglycemia management is essential to optimize patient outcomes.

Due to complications associated with oral antihyperglycemic agents in the inpatient setting, insulin is often used as the sole agent in inpatient hyperglycemia management [8]. Sliding scale insulin has been a common hyperglycemia strategy used in the United States as early as the 1930s. Despite evidence demonstrating no clinical benefit with this strategy, sliding scale insulin has remained pervasive in clinical practice [9]. Sliding scale insulin practices a reactive hyperglycemia management 
style that has been associated with higher rates of hypoglycemic events, suboptimal glycemic control, and longer hospital stays compared to basal-bolus insulin strategies. In basal-bolus insulin strategies, long-acting basal insulin provides stable plasma insulin concentrations and stable fasting hyperglycemia control. The bolus component of basal-bolus insulin strategies is comprised of rapid-acting insulin intended to control postprandial hyperglycemia induced by nutritional intake [10].

The basal-bolus insulin strategy has demonstrated superior hyperglycemia control compared to sliding scale in controlled trials evaluating multiple type 2 diabetic populations, including general surgery and non-critically ill patients [11,12]. Basal-bolus insulin regimens have even been compared to pre-mixed insulin's (i.e. 30\% regular insulin with 70\% NPH insulin) in a randomized controlled trial, demonstrating a significantly reduced risk for hypoglycemia ( $24 \%$ vs $64 \%$, p <0.001) without any difference in glycemic control [13]. In non-critically ill patients with type 2 diabetes mellitus, the RABBIT-2 trial demonstrated significant improvement in glycemic control with basal-bolus-correction insulin regimens without an increase in hypoglycemia or length of stay compared to sliding-scale regular insulin [12]. Therefore, current guidelines recommend basal-bolus-correction insulin strategies over sliding scale insulin for inpatient hyperglycemia management. The 2016 American Diabetes Association (ADA) guidelines recommend initiating insulin therapy for persistent hyperglycemia at a threshold of blood glucose levels $>180 \mathrm{mg} /$ $\mathrm{dL}$, with a goal of $140-180 \mathrm{mg} / \mathrm{dL}$. For non-critically ill patients, basal-bolus-correction insulin regimens are recommended with good nutritional intake; the use of sliding scale insulin only is strongly discouraged [14].

\section{Background}

Current ADA guidelines recommend the use of routine structured order sets that include computerized advice for glucose control [14]. At our institution, sliding scale insulin was previously the only insulin option available on medicine floor admission order sets. Separate orders were required for basal insulin when needed for hyperglycemia management. This often led to a postponed addition of basal insulin to hyperglycemia regimens and delayed insulin administration due to missing orders. To address difficulties with hyperglycemia management, the medicine department at our institution developed a new hyperglycemia protocol (Appendix 1). Thereafter, in April 2016, a new admission insulin order set containing basalbolus-correction ordering options was implemented to facilitate prescribing per protocol for inpatient hyperglycemia management in non-critically ill patients (Figure 1).

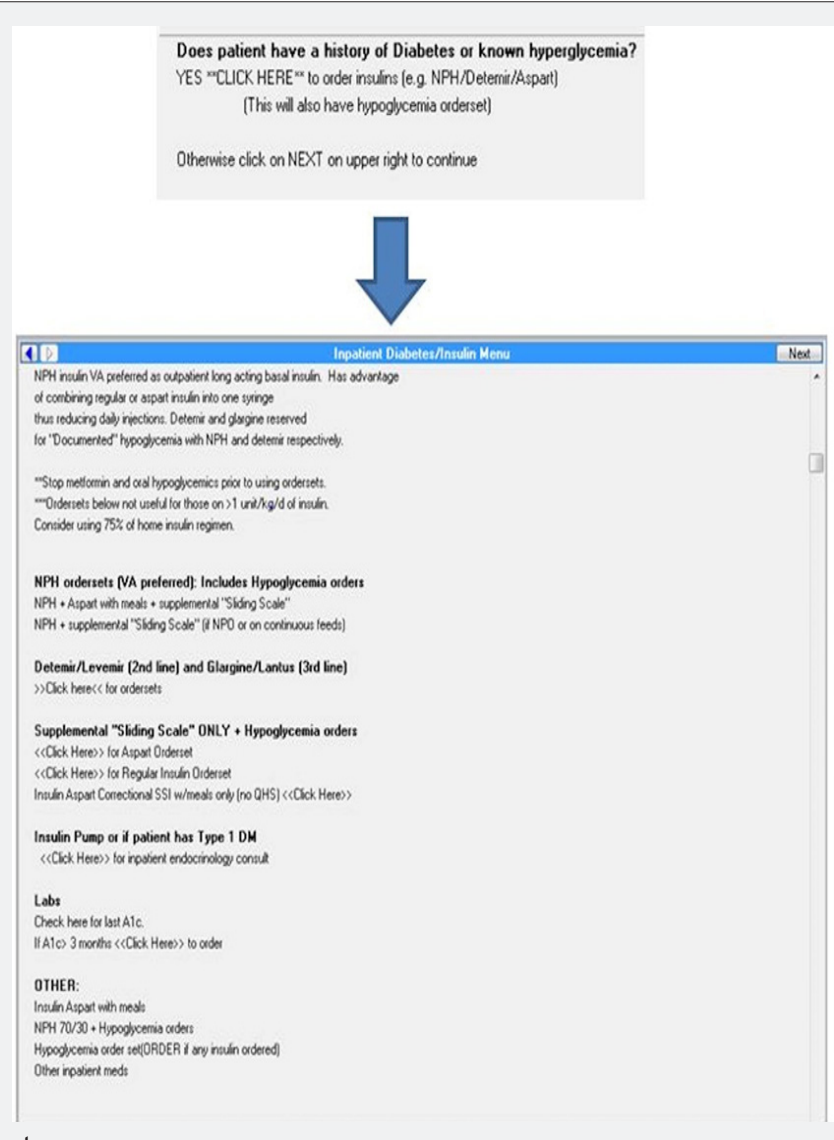

Figure 1: Admission insulin order set.

Providers are prompted to evaluate if the patient has a history of diabetes or is admitted with hyperglycemia. Suggestions to discontinue oral antihyperglycemics and order current $\mathrm{A} 1 \mathrm{C}$ values (if no previous $\mathrm{A} 1 \mathrm{C}$ in the past 3 months) are also provided. Providers then have the opportunity to directly order basal-bolus-correction insulin, as indicated, upon admission. 


\section{Methods}

\section{Study design}

This is a retrospective, single-center, observational study of veterans. The study protocol was formally reviewed and exempted by the university-affiliated institutional review board. Patients admitted between August 1, 2015 to September 30, 2015 (pre-implementation) and August 1, 2016 to September 30, 2016 (post-implementation) were identified through an electronic medical record review of patients admitted to nonICU or non-surgical wards. Patients were evaluated pre- and post-protocol implementation. Glycemic management in the pre-implementation group was determined by individual physician discretion. A 4-month lead-in time from protocol implementation was allowed for staff acclimation to the protocol and training of incoming house staff in July 2016.

\section{Study population}

Patients age $>18$ years were included if admitted to a general medicine ward for at least 3 days with a history of type 2 diabetes or admission blood glucose $>180 \mathrm{mg} / \mathrm{dL}$. Patients were excluded if admitted to intensive care or surgical units during hospitalization, identified to have a history of type I diabetes, treated for diabetic ketoacidosis, pregnant, or allergic to insulin.

\section{Outcomes}

The primary endpoint was mean hospitalization glucose level compared between the pre- and post-implementation groups. Secondary endpoints included percentage of patients with average hospitalization glucose $<180 \mathrm{mg} / \mathrm{dL}$, percentage of basal insulin utilization, percentage of sliding scale insulin only utilization, 30-day mortality, length of stay, and hypoglycemia incidence. A hypoglycemic event was defined as $>1$ consecutive blood glucose reading of $<70 \mathrm{mg} / \mathrm{dL}$. A planned subgroup analysis on average hospitalization blood glucose in patients receiving corticosteroids was also performed.

\section{Statistical analysis}

Categorical data were compared using Fisher's exact test. Continuous data were compared using student $t$ test if normally distributed and the Mann-Whitney $U$ test if not normally distributed. Normally distributed data were described using mean \pm SD. Non-normally distributed data were described using median values and interquartile ranges (IQR). The primary outcome was compared using the Mann-Whitney $U$ tests for independent samples. A p-value of $<0.05$ was considered to be statistically significant. Means, standard deviations, medians, and counts were used for descriptive statistics.

\section{Results}

A total of 2407 patients in the pre-implementation group, and 2417 patients in the post-implementation group were initially identified in the EMR. Patients were randomly evaluated to determine study inclusion. A total of 699 evaluated patients met exclusion criteria or did not match inclusion criteria. A total of 100 patients in the pre- and post-implementation groups were identified. Background characteristics, including pre-admission A1C and home antihyperglycemic regimens, were found to be similar in both groups (Table $1 \& 2$ ).

Table 1: Baseline characteristics.

\begin{tabular}{|c|c|c|c|}
\hline Baseline Characteristics & Pre-protocol $(n=100)$ & Post-protocol $(n=100)$ & p-value \\
\hline Mean age, years \pm SD & $67.1 \pm 11.1$ & $67.5 \pm 10.1$ & 0.82 \\
\hline Male gender, \% & 96 & 97 & 1 \\
\hline Mean BMI, kg \pm SD & $30.1+7.1$ & $30.6+7.2$ & 0.62 \\
\hline Median A1C, \%(IQR) & $8.0(6.7-9.3)$ & $7.5(6.5-8.7)$ & 0.08 \\
\hline Home basal insulin only, \% & 18 & 13 & 0.44 \\
\hline $\begin{array}{l}\text { Home basal plus prandial insulin, } \\
\qquad \%\end{array}$ & 19 & 29 & 0.14 \\
\hline $\begin{array}{l}\text { Home basal plus non-insulin } \\
\text { medication, } \%\end{array}$ & 10 & 9 & 0.82 \\
\hline $\begin{array}{c}\text { Home PO/non-insulin medication, } \\
\%\end{array}$ & 38 & 33 & 0.56 \\
\hline $\begin{array}{c}\text { No antihyperglycemic medication, } \\
\%\end{array}$ & 15 & 16 & 1 \\
\hline $\begin{array}{c}\text { Median admission blood glucose, } \\
\mathrm{mg} / \mathrm{dL}(\mathrm{IQR})\end{array}$ & $188(121.5-222.5)$ & $181(120.8-213.3)$ & 0.71 \\
\hline
\end{tabular}


Table 2: Outcomes.

\begin{tabular}{|c|c|c|c|}
\hline Outcome & Pre-protocol $(n=100)$ & Post-protocol $(n=100)$ & p-value \\
\hline \multicolumn{4}{|c|}{ Primary Outcome } \\
\hline $\begin{array}{l}\text { Mean hospital blood glucose } \\
\text { averages, } \mathrm{mg} / \mathrm{dL} \pm \mathrm{SD}\end{array}$ & $177 \pm 55.3$ & $169 \pm 48.4$ & 0.33 \\
\hline \multicolumn{4}{|c|}{ Secondary Outcomes } \\
\hline $\begin{array}{l}\text { Mean hospitalization glucose } \\
<180 \mathrm{mg} / \mathrm{dL} \text {, OR }(95 \% \mathrm{CI})\end{array}$ & 55 & 66 & 0.15 \\
\hline $\begin{array}{c}\text { Basal insulin use during } \\
\text { hospitalization, OR ( } 95 \% \mathrm{CI})\end{array}$ & 43 & 44 & 1 \\
\hline $\begin{array}{l}\text { Sliding scale insulin use only } \\
\text { during hospitalization, OR } \\
(95 \% \mathrm{CI})\end{array}$ & 52 & 47 & 0.48 \\
\hline 30-day mortality, OR (95\%CI) & 3 & 1 & 0.25 \\
\hline Median length of stay, days (IQR) & $5(3.8-7.0)$ & $4(4.0-7.0)$ & 0.5 \\
\hline Hypoglycemic episodes, no. & 27 & 24 & 0.75 \\
\hline \multicolumn{4}{|c|}{ Subanalysis in Patients Prescribed Corticosteroids } \\
\hline Outcome & Pre-protocol $(n=7)$ & Post-protocol $(n=8)$ & p-value \\
\hline $\begin{array}{l}\text { Mean hospitalization glucose, } \mathrm{mg} / \\
\mathrm{dL} \pm \mathrm{SD}\end{array}$ & $228 \pm 84.8$ & $185 \pm 74.4$ & 0.32 \\
\hline
\end{tabular}

\section{Efficacy}

Patients in the post-protocol were found to have lower average hospitalization glucose, but this was not found to be statistically significant $(177+55.3$ vs. $169+48.4 \mathrm{mg} / \mathrm{dL}, \mathrm{p}=0.33)$. Additionally, more patients in the post-protocol group had mean hospitalization glucose $<180 \mathrm{mg} / \mathrm{dL}$, indicating greater hyperglycemic control, though this was also not statistically significant ( $55 \%$ vs $66 \%, \mathrm{p}=0.15)$. Despite indications of hyperglycemic improvement in the post-implementation group, basal insulin utilization did not change from the pre- to postimplementation periods ( $43 \%$ vs $44 \%, \mathrm{p}=1.00$ ). Furthermore, there was no difference in sliding scale insulin monotherapy utilization, although a non-significant decrease from pre- to postimplementation was observed ( $52 \%$ vs $47 \%$, p-value $=0.48$ ).

There was no difference in the number of patients receiving corticosteroids between the two groups (7 vs. 8 patients, $\mathrm{p}=1.00$ ). Glycemic control in patients receiving corticosteroids appeared to be improved in the post-implementation group compared to pre-implementation (185 vs. $228 \mathrm{mg} / \mathrm{dL}, \mathrm{p}=0.32$ ), but this difference was not significant and is limited by a small sample size.

\section{Safety}

Despite non-significant indications of improved hyperglycemia control, there was no significant difference in hypoglycemic episodes from the pre- to post-implementation periods ( 27 vs 24 events, $\mathrm{p}=0.75$ ). There was also no significant difference in the median length of stay between groups ( 5 vs. 4 days, $p$-value $=0.50$ ) or overall 30 -day mortality ( 3 vs 1 deaths, $\mathrm{p}=0.25$ ).

\section{Discussion}

Although basal-bolus-correction insulin strategies for inpatient hyperglycemia management have demonstrated benefit in previous literature and are recommended by current 
guidelines, its implementation appears to have some barriers [11-14].

In this study, a trend towards improved hyperglycemia management using the newly implemented admission order set was observed, but no significant differences were found. It also appears that the new admission order set had no impact on basal insulin ordering. This was unusual considering there were more patients in the post-implementation group who were initially on home basal insulin regimens, though this difference was not significant. Although no significant improvement in hyperglycemia control was observed, there were also no differences in adverse events such as hypoglycemia, which is consistent with previous literature [12]. A subgroup analysis on patients receiving corticosteroids was pre-planned in this study. The number of patients treated with corticosteroids was similar between groups and no significant difference in glucose control was found, but the sample size was very small, limiting any generalizations of the impact of basal-bolus-correction insulin strategies on glucocorticoid-induced hyperglycemia.

A similar insulin protocol evaluation study at another Veteran Affairs Medical Center found that their implementation of a basal-bolus-correction insulin protocol significantly reduced hypoglycemic events. However, mean blood glucose values increased [15]. While their study showed that protocol implementation could improve patient safety by decreasing hypoglycemic events, the optimal protocol design for hyperglycemia management is still unclear. Design and implementation may be dependent on many institution-specific factors such as compliance, staff education, and workflow processes. Through the development of a hyperglycemia protocol and the implementation of a new admission insulin order set in this study, basal-bolus-correction insulin ordering recommendations are more consistently and readily available for providers to utilize in hyperglycemia management.

This study reflects real-life implementation of a hyperglycemia protocol and was well matched between the pre- and post-protocol groups. Interestingly, baseline A1C levels in the pre- and post-implementation groups were not elevated to a degree that would warrant consistent use of basal insulin for glycemic control. Both groups had a baseline $\mathrm{A} 1 \mathrm{C}<8 \%$, which is approximately equal to an average glucose of $183 \mathrm{mg} /$ $\mathrm{dL}$, and approximately $50 \%$ of patients in both groups did not require home basal insulin [16]. This implicates that perhaps the majority of patients in this study could have achieved adequate inpatient glycemic control with sliding scale insulin alone, explaining the unchanged rate of basal insulin utilization despite its addition to the admission order set.

Overall, the results of this study are generalizable to a large population of hyperglycemia inpatients, but more specifically to those in the non-critically ill setting receiving care at an academic medical center where house staff rotation is common. This study is limited primarily by its failure to measure adherence. Inappropriate dosing, frequency of dose adjustments, and nursing administration of dosages were not analyzed but may have impacted overall glycemic control. The study also included a small sample size and retrospective design.

Another potential limitation of this study is in adequate time allotment for house staff education prior to post-implementation analysis. Post-protocol analysis was performed only 5 months after implementation, and only one month after the introduction of new house staff. In retrospect, this analysis time may not have been sufficient to ensure appropriate implementation of the evaluated order set and protocol.

Most importantly, staff feedback regarding the order set and protocols from this study have revealed several barriers to hyperglycemia protocol implementation. These barriers occurred at multiple interdisciplinary levels of care, including

a) Inappropriate insulin adjustments by house staff due to fear of hypoglycemia and

b) Improper nursing insulin administration in patients with NPO diets.

For example, persistent hyperglycemia due to extremely conservative up titration of insulin dosages by house staff was reported. These observations further revealed a general fear of hypoglycemia. The risk of hypoglycemia associated with basalbolus-correction insulin strategies, however, is not different than that of sliding scale insulin in non-critically ill patients [12]. The management of hypoglycemic episodes with frequent glucose monitoring by nursing staff is also potentially more safe and effective in the inpatient setting compared to patient self-care.

Misconceptions regarding insulin administration in NPO patients were also discovered. Nursing requests to hold basal insulin doses in NPO patients were reported, despite the intended long-acting baseline glycemic control associated with basal insulin. Furthermore, these nursing requests were approved by house staff, leading to inappropriate and suboptimal hyperglycemia control. It was also found that correctional sliding scale doses of rapid-acting insulin were occasionally held in NPO patients, despite its intended purpose of glucose level "correction" independent of nutritional intake. This problem may be associated with the fact that "bolus" rapidacting insulin's typically withheld in NPO patients are identical to the correctional rapid-acting insulin. Correctional insulin at our institution is scheduled as "three times a day before meals" to standardize administration times with pre-prandial rapidacting insulin administration times in patients with a regular diet. Despite explicit statements to give correctional insulin in NPO patients on electronic orders, "before meals" administration times may mislead nursing staff to hold correctional insulin doses, as NPO patients will not receive meals and therefore do not match administration instructions. 
Since the completion of this study, several initiatives to guide future directions have been implemented. Regular education for house staff regarding proper hyperglycemia management and insulin dose initiation/titration (per protocol/ ADA guidelines) has been implemented in collaboration with endocrine staff. House staff has also requested reminders about the availability of the basal-bolus-correction insulin order set and hyperglycemia protocol prior to all general medicine rotations. Inpatient hyperglycemia management education for nursing staff is also in development as a result of this study in order to improve outcomes from a multidisciplinary approach. Due to the discovered misinterpretations of correctional insulin instructions, administration timing will also be reviewed to determine optimal administration instructions for nursing staff. Re-evaluation of inpatient glycemic control after establishment of multidisciplinary education is warranted. Evaluation of admission insulin order set efficacy in a population with higher baseline glucose levels may also provide clearer insight into basal-bolus-correction insulin efficacy and utilization.

\section{Conclusion}

The newly implemented basal-bolus-correction insulin order set was not associated with any difference in inpatient hyperglycemia control. Education at multiple interdisciplinary levels appears to be a crucial requirement for effective hyperglycemia protocol implementation and improved glycemic control.

\section{Acknowledgements}

The authors would like to acknowledge the reviewers for ensuring the quality of this publication.

\section{Key Points}

a) Inpatient hyperglycemia is associated with worse clinical outcomes, including increased rates of infection, longer lengths of stay, and increased mortality.

b) Previous literature and current guidelines recommend basal-bolus-correction insulin strategies for optimal inpatient hyperglycemia management without increased adverse effects.

c) Education at multiple interdisciplinary levels appears to be a crucial requirement for effective hyperglycemia protocol implementation and improved glycemic control.

\section{References}

1. Fraze T, Jiang HJ, Burgess J (2010) Hospital Stays for Patients with Diabetes, 2008: Statistical Brief \#93. Healthcare Cost and Utilization
Project (HCUP). Rockville, MD: Agency for Healthcare Research and Quality (US).

2. Dungan KM, Braithwaite SS, Preiser JC (2009) Stress hyperglycaemia. Lancet 373(9677): 1798-1807.

3. Gosmanov AR (2016) A practical and evidence-based approach to management of inpatient diabetes in non-critically ill patients and special clinical populations. J Clin Transl Endocrinol 5: 1-6.

4. Fathallah N, Slim R, Larif S, Hmouda H, Ben Salem C (2015) DrugInduced Hyperglycaemia and Diabetes. Drug Saf 38(12): 1153-1168.

5. Lansang MC, Umpierrez GE (2016) Inpatient hyperglycemia management: A practical review for primary medical and surgical teams. Cleve Clin J Med 83(5 Suppl 1): S34-S43.

6. Ainla T, Baburin A, Teesalu R, Rahu M (2005) The association between hyperglycaemia on admission and 180-day mortality in acute myocardial infarction patients with and without diabetes. Diabet Med 22(10): 1321-1325.

7. McAlister FA, Majumdar SR, Blitz S, Rowe BH, Romney J, et al. (2005) The relation between hyperglycemia and outcomes in 2,471 patients admit- ted to the hospital with community- acquired pneumonia. Diabetes Care 28(4): 810-815.

8. Magaji V, Johnston J (2011) Inpatient management of hyperglycemia and diabetes. Clinical Diabetes 29(1): 3-9.

9. Nau KC, Lorenzetti RC, Cucuzzella M, Devine T, Kline J (2010) Glycemic control in hospitalized patients not in intensive care: beyond slidingscale insulin. Am Fam Physician 81(9): 1130-1135.

10. Horton ES (2009) Defining the role of basal and prandial insulin for optimal glycemic control. J Am Coll Cardiol 53(5 Suppl): S21-S27.

11. Umpierrez GE, Smiley D, Jacobs S, Peng L, Temponi A, et al. (2011) Randomized study of basal-bolus insulin therapy in the inpatient management of patients with type 2 diabetes undergoing general surgery (RABBIT 2 surgery). Diabetes Care 34(2): 256-261.

12. Umpierrez GE, Smiley D, Zisman A, Prieto LM, Palacio A, et al. (2007) Randomized study of basal-bolus insulin therapy in the inpatient management of patients with type 2 diabetes (RABBIT 2 trial). Diabetes Care 30(9): 2181-2186.

13. Bellido V, Suarez L, Rodriguez MG, Sanchez C, Dieguez M, et al. (2015) Comparison of Basal-Bolus and Premixed Insulin Regimens in Hospitalized Patients With Type 2 Diabetes. Diabetes Care 38(12): 2211-2216.

14. American Diabetes Association (2016) 13. Diabetes Care in the Hospital. Diabetes Care 39 Suppl 1: S99-S104.

15. Chen HJ, Steinke DT, Karounos DG, Lane MT, Matson AW (2010) Intensive insulin protocol implementation and outcomes in the medical and surgical wards at a Veterans Affairs Medical Center. Ann Pharmacother 44(2): 249-256.

16. Sikaris K (2009) The correlation of hemoglobin A1c to blood glucose. J Diabetes Sci Technol 3(3): 429-438. 


\section{INPATIENT MANAgement OF TyPE II Diabetes AND HyPERglycemia}

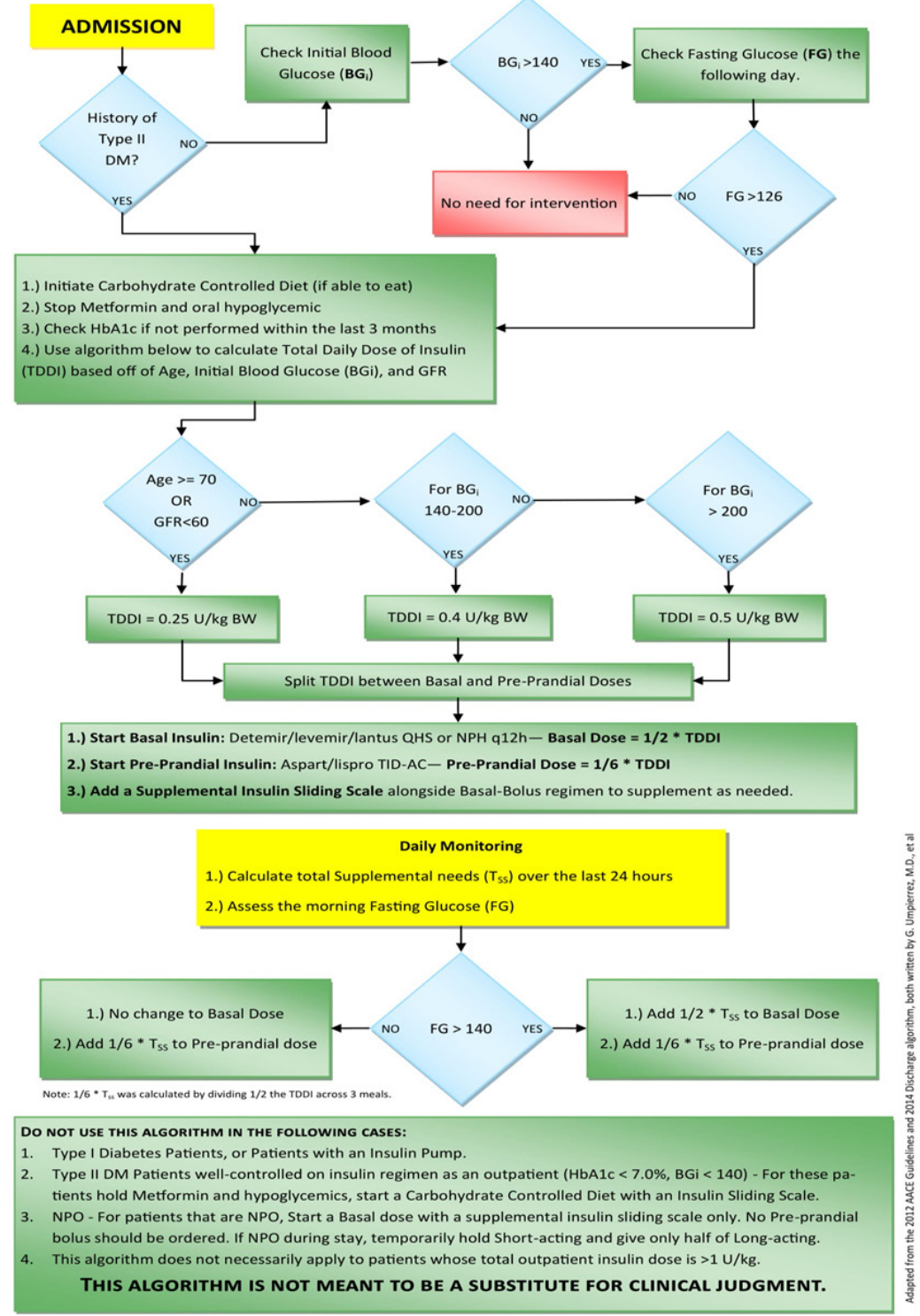

Appendix 1: Alnpatient hyperglycemia management protocol.

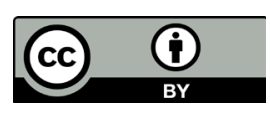

This work is licensed under Creative Commons Attribution 4.0 License DOI: 10.19080/JOJCS.2018.07.555701

\section{Your next submission with Juniper Publishers will reach you the below assets}

- Quality Editorial service

- Swift Peer Review

- Reprints availability

- E-prints Service

- Manuscript Podcast for convenient understanding

- Global attainment for your research

- Manuscript accessibility in different formats ( Pdf, E-pub, Full Text, Audio)

- Unceasing customer service

Track the below URL for one-step submission https://juniperpublishers.com/online-submission.php 